\title{
Drug switch because of treatment-related adverse side effects in endocrine adjuvant breast cancer therapy: how often and how often does it work?
}

\author{
Uwe Güth • Mary Elizabeth Myrick • \\ Andreas Schötzau • Nerbil Kilic • \\ Seraina Margaretha Schmid
}

Received: 31 May 2011/Accepted: 29 June 2011/Published online: 13 July 2011

(C) Springer Science+Business Media, LLC. 2011

\begin{abstract}
Therapy-related adverse side effects are a main reason for non-persistence to adjuvant endocrine breast cancer therapy. This study reports frequency of drug-related adverse side effects that were so severe that a modification of the therapy was necessary. We evaluated how many patients discontinued adjuvant endocrine therapy because of these side effects (non-persistence). Last, we analyzed how often a drug switch was undertaken for this reason and how often this measure led to the patient successfully continuing their endocrine therapy. Data concerning all postmenopausal breast cancer patients ( $\leq 80$ years), who initiated endocrine adjuvant therapy between 1998 and 2008 in a Swiss breast center $(n=400)$, were analyzed. Out of these 400 women, $37(9.3 \%)$ were defined as being non-persistent to the therapy; out of these, 24 (64.9\%) because of therapy-related side effects. About 78 patients (19.5\%) suffered from severe therapy-related side effects that made a modification of
\end{abstract}

U. Güth · M. E. Myrick · N. Kilic · S. M. Schmid

Department of Gynecology and Obstetrics, University Hospital

Basel (UHB), Spitalstrasse 21, 4031 Basel, Switzerland

U. Güth · N. Kilic $\cdot$ S. M. Schmid

Breast Center, University Hospital Basel, Spitalstrasse 21,

4031 Basel, Switzerland

U. Güth $(\bowtie)$

Department of Gynecology and Obstetrics, Cantonal Hospital

Winterthur, Brauerstrasse 15, 8401 Winterthur, Switzerland

e-mail: uwe.gueth@unibas.ch

\section{A. Schötzau}

Schötzau \& Simmen Institute for Biomathematics, Malzgasse 9, 4052 Basel, Switzerland

\section{N. Kilic}

Department of Oncology, University Hospital Basel,

Petersgraben 4, 4031 Basel, Switzerland therapy necessary. Out of these 78 cases, 14 patients (17.9\%) stopped the therapy without attempting a drug switch (nonpersistence). In 64 patients (82.1\%; $16 \%$ of all women who started endocrine therapy), a drug switch was undertaken. Out of these 64 cases, in 52 cases (81.3\%) endocrine therapy was completed after therapy modification. Patients who reported one major adverse effect were more likely to continue the endocrine therapy after a drug switch $(P=0.048)$ compared with those who suffered from at least two different side effects. In 10 of the 64 cases (15.6\%), modification of the therapy was not successful and the patients stopped the treatment prematurely (non-persistence) because of ongoing side effects. In cases when therapy-related side effects occur, a drug switch is a promising step to further improve persistence and, by doing so, the outcome of breast cancer patients.

Keywords Breast cancer - Endocrine therapy - Adverse events $\cdot$ Switch $\cdot$ Persistence $\cdot$ Adherence

\section{Introduction}

Since the late 1990s, international guidelines recommend a full 5 years of adjuvant systemic endocrine treatment with tamoxifen for the vast majority of postmenopausal patients with hormonal receptor (HR) positive breast carcinomas [1]. More recently, clinical studies demonstrated additional benefit with the third-generation aromatase inhibitors (AIs) in postmenopausal women, either as initial management also for 5 years, as sequential therapy following $2-3$ years use of tamoxifen, or as extended therapy following 5 years of tamoxifen.

In long-term therapies, however, there are a multitude of factors and clinical situations that threaten and prevent completion of the targeted 5-year treatment. The main 
causes noted by patients for non-persistence/non-adherence to therapy are drug-related adverse side effects such as arthralgia, hot flashes and gynecologic symptoms [2-7]. Clinicians who are experienced in the follow-up of breast cancer patients are aware of these issues and can offer a multitude of nonpharmacological and pharmacological treatment strategies, which alleviate the symptoms of side effects [2-7]. In some cases, a drug switch is a promising step [2]. However, to the best of our knowledge, there is only one study which evaluated frequency and outcome of side effect-related drug switches [8].

This study reports how often postmenopausal women (diagnosed in a ten-year period from 1998 to 2008 in a Swiss breast center) suffered from drug-related adverse side effects in such a severity that a modification of the therapy was necessary. Furthermore, we evaluated how many patients discontinued their adjuvant endocrine therapy due to these side effects (non-persistence). Lastly, we analyzed how often a drug switch was undertaken for this reason and how often this measure led to the patient successfully continuing their endocrine therapy.

\section{Patients and methods}

Data concerning all postmenopausal non-metastatic breast cancer patients up to and including the age of 80 years, who received surgical therapy between 1998 and 2008 at the Department of Gynecology and Obstetrics of the University Hospital Basel (Basel, Switzerland) and was collected in the institutional prospective relational Basel Breast Cancer Database (BBCD) form the basis of the current analysis. Of these 523 patients, 427 had hormonal receptor (HR) positive carcinomas (81.6\%) and 96 had HR negative tumors (18.4\%). The 427 patients with HR positive carcinomas were evaluated in this study. We had complete follow-up in 421 of these patients and six patients were lost to follow-up after a median observation time of 16.5 months (range: $1-45$ months).

The following clinicopathological and treatment data, which is summarized in Table 1, was available for all patients: age at initial diagnosis, tumor stage according to the American Joint Committee on Cancer (AJCC)/International Union Against Cancer (UICC) TNM Classification [9, 10], histological subtype, grading, estrogen receptor (ER) and progesterone receptor (PR) status, surgery type, and receipt of adjuvant chemotherapy and/or radiation. HER-2/neu status has been routinely assessed for all patients since 2002; in our study group this variable was available for 394 patients $(92.3 \%)$.

The treatment recommendations for all patients were based on the decision of the interdisciplinary tumor board of the University Hospital Basel. As of 1997, adjuvant
Table 1 Clinicopathologic and treatment characteristics of 427 postmenopausal women with hormonal receptor positive breast cancer

\begin{tabular}{|c|c|}
\hline Variable & Number $(\%)$ \\
\hline \multicolumn{2}{|l|}{ Age (years) } \\
\hline Mean & 65.9 \\
\hline Range & $46-80$ \\
\hline$\leq 60$ years & $128(30.0)$ \\
\hline $61-75$ & 165 (38.6) \\
\hline$>75$ years & $134(31.4)$ \\
\hline \multicolumn{2}{|l|}{ Hormonal receptor status } \\
\hline $\mathrm{ER}+\mathrm{PR}+$ & $311(72.8)$ \\
\hline $\mathrm{ER}+\mathrm{PR}-$ & $114(26.7)$ \\
\hline $\mathrm{ER}-\mathrm{PR}+$ & $2(0.5)$ \\
\hline \multicolumn{2}{|l|}{ Grading } \\
\hline G1 & $92(21.6)$ \\
\hline $\mathrm{G} 2$ & $235(55.0)$ \\
\hline G3 & $93(21.8)$ \\
\hline Not applicable & $7(1.6)$ \\
\hline \multicolumn{2}{|l|}{ HER-2 neu status } \\
\hline Known & $394(92.3)$ \\
\hline Positive & $49(12.4)$ \\
\hline \multicolumn{2}{|l|}{ Histologic subtype } \\
\hline Ductal invasive & $301(70.5)$ \\
\hline Lobular invasive & $85(19.9)$ \\
\hline Rare types & $41(9.6)$ \\
\hline \multicolumn{2}{|l|}{ AJCC/UICC stage ${ }^{a}$} \\
\hline I & $209(49.0)$ \\
\hline II & $166(38.9)$ \\
\hline III & $52(12.1)$ \\
\hline \multicolumn{2}{|l|}{ Type of surgery } \\
\hline Mastectomy + ALND & $111(26.0)$ \\
\hline Mastectomy + SLND & $26(6.1)$ \\
\hline BCT + ALND & $149(34.9)$ \\
\hline $\mathrm{BCT}+\mathrm{SLND}$ & $124(29.0)$ \\
\hline Mastectomy only & $11(2.6)$ \\
\hline Tumorectomy only & $6(1.4)$ \\
\hline \multicolumn{2}{|c|}{ Systemic treatment other than adjuvant endocrine therapy } \\
\hline Previous adjuvant chemotherapy & $70(16.4)$ \\
\hline Neoadjuvant chemotherapy & $4(0.9)$ \\
\hline Neoadjuvant endocrine therapy & $2(0.5)$ \\
\hline Adjuvant treatment with trastuzumab & $12(2.8)$ \\
\hline Adjuvant radiotherapy & $308(72.1)$ \\
\hline
\end{tabular}

$E R$ estrogen receptor, $P R$ progesterone receptor, AJCC American Joint Committee on Cancer, UICC International Union Against Cancer $[9,10], A L N D$ axillary lymph node dissection, SLND sentinel lymph node dissection, $B C T$ breast-conserving therapy

${ }^{a}$ In six patients, where neoadjuvant therapy was performed, the ypT and ypN status were used for stage grouping

endocrine therapy has been the standard recommendation for all HR positive patients, with few exceptions. All patients received a comprehensive consultation at the 
Table 2 Course of endocrine therapy

\section{$B C$ breast cancer}

${ }^{\text {a }}$ Two patients who were lost to follow-up but had an observation time of more than 30 months were allocated to a location of follow-up

\begin{tabular}{|c|c|c|c|}
\hline & $\begin{array}{l}\text { Number } \\
(\%)\end{array}$ & $\begin{array}{l}\text { Mean age } \\
\text { (range) }\end{array}$ & $\begin{array}{l}\text { Median duration } \\
\text { of therapy } \\
\text { (months) }\end{array}$ \\
\hline Entire study group & 427 & & \\
\hline No endocrine therapy recommended & $8(1.9)$ & $68.5(52-77)$ & \\
\hline Patients where endocrine therapy was recommended & $419(100)$ & & \\
\hline Patients refused to initiate therapy & $19(4.5)$ & $66.7(52-79)$ & \\
\hline Patients who initiated endocrine therapy & $400(100)$ & & \\
\hline \multicolumn{4}{|l|}{ Initial agent prescribed } \\
\hline Tamoxifen & $265(66.3)$ & & \\
\hline Anastrozole & $73(18.3)$ & & \\
\hline Letrozole & $42(10.5)$ & & \\
\hline Exemestane & $3(0.7)$ & & \\
\hline Fulvestrant & $1(0.2)$ & & \\
\hline Blinded study medication (BIG 1-98 trial) & $16(4.0)$ & & \\
\hline Therapy fully completed & $299(74.8)$ & $65.4(47-80)$ & \\
\hline $\begin{array}{l}\text { Therapy discontinued because of death } \\
\text { (i.e., completed) }\end{array}$ & $13(3.3)$ & $68.5(52-79)$ & $14(2-48)$ \\
\hline $\begin{array}{l}\text { Therapy discontinued because of } \mathrm{BC} \\
\text { recurrence (i.e., completed) }\end{array}$ & $40(10.0)$ & $66.6(47-80)$ & $21.5(3-58)$ \\
\hline $\begin{array}{l}\text { Therapy discontinued because of medical } \\
\text { reasons independent from BC and adverse effects from } \\
\text { the endocrine therapy (i.e., completed) }\end{array}$ & $5(1.3)$ & $69.6(60-75)$ & $28(25-52)$ \\
\hline Non-persistence & $37(9.3)$ & $67.1(49-80)$ & $15.5(1-50)$ \\
\hline Lost to follow-up & $6(1.5)$ & & \\
\hline Location of follow-up & $400(100)$ & & \\
\hline Own oncologic unit & $268(67.0)$ & & \\
\hline External oncologic unit & $40(10.0)$ & & \\
\hline General practitioner & $88(22.0)$ & & \\
\hline Unknown $^{\mathrm{a}}$ & $4(1.0)$ & & \\
\hline
\end{tabular}

departmental oncology unit, during which treatment indication and duration, as well as the potential adverse effects, were extensively discussed.

In order to systematically evaluate the different clinical situations during the course of adjuvant endocrine therapy, we created the following subdivisions (Table 2):

A. Patients who did not initiate therapy $(n=27)$.

This subgroup includes the patients to whom endocrine therapy was not recommended $(n=8)$, and the patients who refused the recommended therapy and never began treatment $(\mathrm{n}=19)$.

B. Patients who initiated therapy $(n=400)$.

Of the 400 patients who initiated endocrine therapy, 149 (37.3\%) fully completed the targeted therapy after a fiveyear course (three patients interrupted therapy for up to three months, one patient for five months) and 44 (11.0\%) had an extended therapy $>5$ years (20 of these with an ongoing therapy at the time of last follow-up in January-March 2011). As it was the intention of our study to evaluate patients who discontinued therapy due to drug-related side effects, which in most cases occurs within the first two years of therapy [11-13], we also included patients with an ongoing therapy who took their medication for at least 30 months ( $n=106 ; 26.5 \%$ ). Further subgroups must also be considered as having completed therapy, although treatment was not administered for the targeted five years: 13 patients discontinued the therapy due to death from causes other than breast cancer (but medication was taken until shortly before death); 40 patients ceased therapy due to breast cancer recurrence and in five cases, the therapy was discontinued by the physician due to serious medical reasons independent from breast cancer disease and therapyrelated adverse effects (advanced age/dementia/need for nursing home care, $n=2$; incurable malignancy other than breast cancer, $n=2$; irreversible coma following severe head trauma, $n=1$ ). 
We distinguished the above-mentioned subgroups from non-persistent patients patients who discontinued the planned mode of treatment and refused to continue further endocrine therapy $(n=37)$. In this context, non-persistence was an intentional action of the patients in most cases.

In this study, we used the term "persistence" and not "adherence". Persistence is defined as the length of time from initiation to discontinuation of treatment; it is a specific aspect of adherence, which is defined as the extent to which patients take medications as prescribed [14-16]. Some other studies defined these terms differently and used compliance, adherence and persistence sometimes interchangeably [4].

The initial endocrine agents prescribed are listed in Table 2. Twenty-nine patients were treated within the randomized, phase III, double-blind Breast International Group (BIG) 1-98 four-arm study (letrozole or tamoxifen as monotherapy or sequential therapy) [17]; the medication was unblinded in 13 of these patients. In 48 patients, there was an intended sequential therapy (switching after 2-3 years of adjuvant tamoxifen therapy to an aromatase inhibitor) outside of a study protocol.

Finally, we recorded the location of treatment and follow-up of the patients (our own oncology unit, external oncology unit, or general practitioner).

Information concerning type and duration of the medication, as well as the reasons for discontinuation, was obtained from the medical record. Patients who had no follow-up at our institution were monitored via telephone. Afterward, contact was made with the treating physician to confirm the patients' statements.

Data collection methods and the study design were approved by the institutional review board.

\section{Statistical analysis}

Comparisons between nominal parameters were made with the Fisher exact test. Comparisons between metric parameters (age) were made with the Wilcoxon rank sum test. To identify factors associated with A) the choice to switch due to therapy-related side effects, and B) a switch that led to a successful continuation of therapy, we created two univariate logistic regression models. Each model included the independent variables year of the initial diagnosis, patient's age, axillary lymph node status, receipt of previous chemotherapy, the antihormonal agent prescribed, the number of the reported adverse effects, and location of follow-up. Odds ratios (OR) with corresponding 95\% confidence intervals $(\mathrm{CI})$ were reported; a $P$-value $<0.05$ was considered significant. Statistical analyses were performed with R Development Core Team software, version 2.5.0 (Vienna, Austria).

\section{Results}

Frequency of non-persistence

Out of the 400 women who started endocrine therapy, 37 $(9.3 \%)$ were non-persistent to the initiated therapy; out of these, $24(64.9 \%)$ due to therapy-related side effects, and $13(35.1 \%)$ due to other reasons. The main reasons for this given by the patients are listed in Table 3 .

Frequency of therapy modification due to therapy-related side effects

Out of the 400 women who started endocrine therapy, in 78 patients $(19.5 \%)$, the therapy-related side effects were so severe, that a modification of the therapy (drug switch or cessation) was indicated. Comparing the patients who suffered from adverse therapy-related side effects that made a modification of the therapy necessary to the ones where this was not the case, there were no relevant differences with regard to age (mean: 64.8 years vs. 66.0 years; $P=0.280$ ) or initial agent taken (tamoxifen: $70.5 \%$ vs. $68.5 \% ; P=0.788)$.

Out of the above-mentioned 78 cases, 14 patients (17.9\%) stopped the therapy without attempting a drug switch (non-persistence). In 64 patients $(82.1 \%$; $16 \%$ of all women who started endocrine therapy), a drug switch was undertaken. In our univariate calculation model (Table 4), the number of major adverse effects was the only significant predictive factor for drug switch $(P=0.044)$.

\section{Effect of drug switch on persistence}

Table 5 lists the sequence of drugs in the switch approaches. Out of the 64 cases where a drug switch was made, in 52 cases (81.3\%) endocrine therapy was completed after therapy modification; out of these, in 37 cases $(71.2 \%)$ one drug switch was made, in 12 cases $(23.1 \%)$ two medication changes were necessary and in three cases $(5.7 \%)$ the medication was changed three times. Table 3 lists the main symptoms diagnosed or reported by the patients who completed therapy after drug switch. Patients who reported one major adverse effect were more likely to continue the endocrine therapy after a drug switch $(P=0.048$, see Table 4) compared to those who suffered from at least two different side effects.

In 12 of the 64 cases $(18.8 \%)$, modification of the therapy was not successful and the patients stopped the treatment prematurely (non-persistence). Ten patients stopped the therapy due to ongoing or further side effects; two women initially continued the therapy but stopped later before the planned five years because they felt that therapy was no more necessary in their situation (both patients 
Table 3 Main reasons for modification of the antihormonal therapy ${ }^{\mathrm{a}}$

\begin{tabular}{lll}
\hline & $\begin{array}{l}\text { Non-persistence: } \\
\text { preterm stop of } \\
\text { the therapy (with or } \\
\text { without drug switch) } \\
n=24\end{array}$ & $\begin{array}{l}\text { Persistence: continuation/ } \\
\text { completion of therapy after } \\
\text { drug switch } n=54\end{array}$ \\
\hline
\end{tabular}

1. Patients who suffered from therapy-related side effects and modified the therapy, $n=78$

General discomfort $\quad 6 \quad 7$

Lack of energy $\quad 2 \quad 5$

Sleeping difficulties $\quad 3 \quad 2$

Night sweats $\quad 1$ -

Nervous feelings $\quad 5 \quad 4$

Mood swings $\quad 3 \quad 5$

Head aches $\quad-\quad 12$

Dizziness $\quad 1 \quad 3$

$\begin{array}{lll}\text { Nausea } & 4 & 4\end{array}$

Paresthesia at extremities $\quad 1 \quad 3$

Visual disorders $\quad 2 \quad 2$

Dermatologic disorders, hair loss $\quad 2 \quad 2$

Gastrointestinal symptoms $\quad 1 \quad 1$

Weight gain $\quad 1 \quad 2$

Hot flashes $\quad 7 \quad 6$

Venous disorders $\quad 1 \quad 2$

Venous thromboembolic events $\quad 1 \quad 5$

Ischemic cerebrovascular events $\quad 1 \quad 1$

Hypertension $\quad 2 \quad 1$

Virilization $\quad-\quad 22$

Endometrial hyperplasia $\quad-\quad 2$

Musculoskeletal events $\quad 4 \quad 25$

(e.g., arthralgia, bone pain)

2. Patients stopped the therapy for reasons other than therapy-related side effects $(n=13)$

Wish for discontinuation, lack of motivation 5

Lack of faith in the therapy 2

Misinformation by physician 1

Error regarding length of therapy 1

Insurance reasons 1

Denial of the cancer diagnosis 1

Alcohol dependency or psychiatric disease $\quad 2$

patient is possible

were older and multimorbid women who wanted to reduce the number of their drugs prescribed).

\section{Discussion}

Adjuvant endocrine treatment for breast cancer has a special status within oncological therapies as its recommended duration is not a few weeks or months, as in chemotherapy, but at least five years. In the case adverse therapy-related events occur, these mean more than only a transient inconvenience for the patients [2]. Since endocrine therapy is a systemic treatment which can affect almost every organ system, there is a broad range of possible therapy-related side effects. Venous thromboembolic events, hot flashes, arthralgia and bone pain, as well as neuropsychiatric, gastrointestinal and gynecologic symptoms are frequently reported adverse effects associated with endocrine therapy. Careful recognition and competent management of these side effects cannot be emphasized enough as adverse events constitute the main reason for non-persistence and nonadherence to endocrine treatment. This field is increasingly becoming a focus of interest [2-7]. Aside from nonpharmacological and pharmacological measures to alleviate or 
Table 4 Univariate relationships between potential predictors and (A) a drug switch when adverse therapy-related side effects occurred and (B) a successful continuation of endocrine therapy after a drug switch

\begin{tabular}{|c|c|c|c|}
\hline Variable & Odds ratio & $95 \% \mathrm{CI}$ & $P$ value \\
\hline \multicolumn{4}{|l|}{ (A) } \\
\hline \multicolumn{4}{|l|}{ Year of the initial diagnosis: } \\
\hline 1998-2002 & Reference & & \\
\hline $2003-2008$ & 2.25 & $0.68-7.47$ & 0.190 \\
\hline Advanced age & $0.85^{\mathrm{a}}$ & $0.56-1.30$ & 0.455 \\
\hline $\begin{array}{l}\text { Positive axillary lymph node } \\
\text { status }\end{array}$ & 0.64 & $0.17-2.36$ & 0.500 \\
\hline Previous chemotherapy & 3.00 & $0.36-25.21$ & 0.312 \\
\hline \multicolumn{4}{|l|}{ Initial antihormonal agent } \\
\hline Tamoxifen & Reference & & \\
\hline AI & 0.48 & $0.15-1.59$ & 0.232 \\
\hline \multicolumn{4}{|c|}{ Number of reported adverse effects } \\
\hline 1 & Reference & & \\
\hline$\geq 2$ & 0.27 & $0.08-0.97$ & 0.044 \\
\hline \multicolumn{4}{|l|}{ Location of follow-up } \\
\hline Oncologic unit & Reference & & \\
\hline General practitioner & 0.41 & $0.11-1.59$ & 0.212 \\
\hline \multicolumn{4}{|l|}{ (B) } \\
\hline \multicolumn{4}{|l|}{ Year of the initial diagnosis } \\
\hline 1998-2002 & Reference & & \\
\hline $2003-2008$ & 1.00 & $0.23-4.39$ & 1.00 \\
\hline Advanced age & $1.15^{\mathrm{a}}$ & $0.71-1.85$ & 0.573 \\
\hline $\begin{array}{l}\text { Positive axillary lymph node } \\
\text { status }\end{array}$ & 1.40 & $0.32-6.13$ & 0.655 \\
\hline Previous chemotherapy & n.a. & n.a. & 0.018 \\
\hline \multicolumn{4}{|l|}{ Initial antihormonal agent } \\
\hline Tamoxifen & Reference & & \\
\hline AI & 2.38 & $0.64-8.88$ & 0.197 \\
\hline \multicolumn{4}{|c|}{ Number of reported adverse effects } \\
\hline 1 & Reference & & \\
\hline$\geq 2$ & 0.26 & $0.07-1.00$ & 0.048 \\
\hline \multicolumn{4}{|l|}{ Location of follow-up } \\
\hline Oncologic unit & Reference & & \\
\hline General practitioner & 1.28 & $0.23-7.14$ & 0.777 \\
\hline
\end{tabular}

AI aromatase inhibitor, n.a. not applicable

a Odds ratio is expressed as the ratio of an increase within 5 years

resolve these side effects, a switch to a different agent is a valid option. However, to the best of our knowledge, there is only one study which evaluated frequency and outcome of side effect-related drug switches [8].

In our study cohort, approximately two third of the patients, who were non-persistent to endocrine therapy, stopped their treatment due to therapy-related side effects. The non-persistence rate in our study, which lies at $9.3 \%$, is clearly in the lowest range of the reported data in adjuvant
Table 5 Sequence of agents in therapy switches

\begin{tabular}{|c|c|c|c|}
\hline & $\begin{array}{l}\text { All } \\
\text { switches }\end{array}$ & $\begin{array}{l}\text { Successful } \\
\text { switches }^{\mathrm{a}}\end{array}$ & $\begin{array}{l}\text { Failed } \\
\text { switches }\end{array}$ \\
\hline $\begin{array}{l}\text { Total number of therapy } \\
\text { switches }\end{array}$ & 82 & $54(65.9)$ & $28(34.1)$ \\
\hline $\begin{array}{l}\text { Tamoxifen } \\
\text { inhibitor }\end{array}$ & 36 & $21(58.3)$ & $15(41.7)$ \\
\hline Tamoxifen $\rightarrow$ letrozole & 25 & 13 & 12 \\
\hline Tamoxifen $\rightarrow$ anastrozole & 9 & 7 & 2 \\
\hline Tamoxifen $\rightarrow$ exemestane & 2 & 1 & 1 \\
\hline $\begin{array}{l}\text { Aromatase } \\
\quad \text { inhibitor } \rightarrow \text { Tamoxifen }\end{array}$ & 17 & $13(76.5)$ & $4(23.5)$ \\
\hline Letrozole $\rightarrow$ tamoxifen & 8 & 7 & 1 \\
\hline Anastrozole $\rightarrow$ tamoxifen & 6 & 5 & 1 \\
\hline Exemestane $\rightarrow$ tamoxifen & 3 & 1 & 2 \\
\hline $\begin{array}{l}\text { Aromatase } \\
\text { inhibitor } \rightarrow \text { Aromatase } \\
\text { inhibitor }\end{array}$ & 29 & $20(69.0)$ & $9(31.0)$ \\
\hline Letrozole $\rightarrow$ anastrozole & 7 & 4 & 3 \\
\hline Letrozole $\rightarrow$ exemestane & 7 & 5 & 2 \\
\hline Anastrozole $\rightarrow$ letrozole & 10 & 8 & 2 \\
\hline Anastrozole $\rightarrow$ exemestane & 5 & 3 & 2 \\
\hline
\end{tabular}

${ }^{a}$ Therapy was continued after drug switch

b Therapy was discontinued or a further switch was made

endocrine breast cancer treatment both in clinical trials [17-20] and in clinical practice settings [11-13, 15, 21-30]. To interpret these results accordingly, one must identify how we defined non-persistence, which is the actual target variable in our study. According to a previous study, we clearly distinguished the terms "discontinuation of therapy" and "non-persistence" and are of the opinion that nonpersistence to a long-term oral therapy is, in general, not simply the act of stopping medication, but rather an intentional action [11]. According to this principle, patients who had to stop therapy due to local or systemic breast cancer recurrence were not defined as being non-persistent. The same holds true for cases where a physician decided to stop the therapy for medical reasons other than breast cancer (e.g. in palliative situation of malignant diseases, dependence on nursing care, severe dementia); this subgroup was introduced in one of our previous publications in the literature regarding therapy persistence/adherence in breast cancer [11]. Furthermore, in accordance with most authors, patients who died within the planned five years of treatment from intercurrent illness and took the medication shortly before death were not considered as non-persistent. We place a great deal of importance on the above-mentioned criteria because non-persistence as an intentional action may be preventable by more intensive care and improved counseling and a certain proportion of these patients may potentially be motivated to maintain therapy; this 
constellation is clearly not relevant in a situation where the discontinuation of therapy was not chosen but was mandatory, for example due to recurrence or the diagnosis of distant metastases. We think that the synonymous use of the terms "discontinuation" and "non-persistence/non-adherence," which was applied by a number of authors [12, 13, $15,21,23-30]$, is a severe methodic error which leads to the fact that patients who had to stop therapy due to liver metastases are categorized in the same group with those who, for example, suffer from hot flashes and those who stopped the therapy because they have a general mistrust in the agents of the western medicine.

It was shown that persistence and adherence to endocrine therapy was influenced by certain factors such as age, adverse effects, patient beliefs about the risks and benefits of drug use, history of medication and good patient-doctor relationship [2-5, 31]. Some of these factors may be influenced by the type of care and expertise of the responsible physician. Since most of the patients in our study had follow-up at the oncology unit of our department, the favorable non-persistence rates may be associated with the fact that all physicians in this unit are not only experienced in the aftercare of oncologic patients but also applied the techniques of patient-centered communication $[32,33]$. For many years, in any follow-up consultation of patients who take adjuvant endocrine treatment, the dialog with the patient has included targeted questions regarding therapy motivation, the importance of adherence and in particular, an open discussion regarding therapy-related side effects. When patients experience distressing symptoms, we carefully evaluate these symptoms and make the patients feel that their complaints are taken seriously while offering non-pharmacological and pharmacological measures to improve the situation. As stated by other authors, a change in therapy may be an effective strategy to improve patient persistence and adherence [2, 34]. In our study, more than $80 \%$ of the patients who required a change of the prescribed agent due to adverse effects could fully complete endocrine therapy in the course of time. In some cases, patience is required and more than one drug switch can be necessary. Not only is a switch between different agent groups (tamoxifen to $\mathrm{AI}$, or $\mathrm{AI}$ to tamoxifen) a possibility, but also a switch within the three different available aromatase inhibitors (letrozole, anastrozole, exemestan) might be a promising approach. In our experience, in cases where a single therapy-related adverse event led to therapy switch, the likelihood that the therapy will be continued to the targeted aim is particularly high. Therefore, patients who suffer from several side effects, in particular a syndrome-like complex from neuropsychiatric symptoms (e.g. sleeping difficulties, lightheaded feeling, headaches, mood swings, irritability, lack of energy, nervous feeling, etc.) run a higher risk of quitting therapy.
In some cases, the side effects are not necessarily severe. There is increasing recognition of the effect of persistent low-grade problems which lead to a relevant chronic fatigue and could potentially decrease the motivation for continuation of therapy (citation from an open letter of a cancer patient to her doctor: "...the little things that get us down"[35]). Correspondingly, patients who suffer from therapy-related side effects after a planned switch from tamoxifen to an AI, show a high degree of persistence. In these cases (in our study cohort: $n=12$ ), a re-switch to tamoxifen, which was previously given for 2-3 years, is an easy step to warrant persistence. In our experience, a switch not only lessens the intensity of adverse side effects in some cases, but might also support drug persistence: certain patients who started a certain drug and experienced side effects, tried another drug, experienced no change or worse side effects and returned to their initial drug (in our study cohort, we observed this in 12 cases). We feel that it is important to accompany these patients during this month-long conflict between eradication of side effects and the motivation to treat a potentially life threatening disease using all possibilities.

We are convinced that great demands are made on the treating physician (both on a professional and interpersonal level) when patients question the therapy in conflicting situations and believe that care in a specialized center can ensure persistence and adherence to therapy.

However, the limitations of our study must be considered. First, our study relies on information obtained by patients " self-report of persistence. It is possible that in some cases the patients who reported continuing their medication had actually stopped taking it and just gave a socially acceptable answer. Furthermore, we defined non-persistence as an intentional action. Atkins et al. demonstrated a high percentage of $55 \%$ of non-adherent patients with the vast majority of women reporting a nonintentional non-adherence, i.e. they often just forgot to take their medication [21]. Waterhouse et al. who examined adherence to tamoxifen therapy found that self reported adherence consistently underestimates non-adherence as determined by more objective measures such as pill count and microelectronic monitoring [29].

Secondly, one might argue that prospective randomized clinical trials have the highest level of evidence in medical literature and might criticize the retrospective approach of our study. On the other hand, large clinical trials, with their extensive case documentation requirements cannot provide exact information regarding persistence and adherence to endocrine therapy in the general setting, since the readiness to participate in a trial already creates a certain selection bias. Furthermore, non-persistence data from clinical trials may not necessarily be transferable to the real situation, since withdrawal of study medication does not imply the 
stop of endocrine therapy and a considerable number of the patients who chose to stop the study medication continued and completed endocrine therapy outside of the trial [11].

Thirdly, one might argue that the number of the patients reported in our study is too low to derive meaningful results. In general, we think that studies on persistence and adherence to therapy, which in principle try to illuminate the complex field of personal motivation to therapy, must be performed in a clinical setting which is able to follow the entire cohort in a very exact and individual way. We think that our database fulfills these requirements much better than epidemiologic studies which might impress with high numbers, but cannot provide an exact individualbased follow-up [12, 25].

\section{Conclusions}

Our data shows that low non-persistence rates can be realistically achieved. In cases when therapy-related side effects occur, a drug switch is a promising step to further improve persistence and, by doing so, the outcome of breast cancer patients [31]. We think that this important issue, which is uncharted territory regarding endocrine therapy of breast cancer up until now, deserves higher attention and requires further data analyses.

Conflict of interest The authors declare that there are no financial or personal relationships with other people or organizations that could inappropriately influence the work reported or the conclusions, implications, or opinions stated.

\section{References}

1. Goldhirsch A, Glick JH, Gelber RD, Senn HJ (1998) Meeting highlights: International Consensus Panel on the Treatment of Primary Breast Cancer. J Natl Cancer Inst 90(21):1601-1608

2. Cella D, Fallowfield LJ (2008) Recognition and management of treatment-related side effects for breast cancer patients receiving adjuvant endocrine therapy. Breast Cancer Res Treat 107(2):167-180

3. Dent SF, Gaspo R, Kissner M, Pritchard KI (2011) Aromatase inhibitor therapy: toxicities and management strategies in the treatment of postmenopausal women with hormone-sensitive early breast cancer. Breast Cancer Res Treat 126(2):295-310

4. Hadji P (2010) Improving compliance and persistence to adjuvant tamoxifen and aromatase inhibitor therapy. Crit Rev Oncol Hematol 73(2):156-166

5. Monnier A (2007) Clinical management of adverse events in adjuvant therapy for hormone-responsive early breast cancer. Ann Oncol 18(Suppl 8):36-44 viii

6. Mortimer JE (2010) Managing the toxicities of the aromatase inhibitors. Curr Opin Obstet Gynecol 22(1):56-60

7. Mouridsen HT (2006) Incidence and management of side effects associated with aromatase inhibitors in the adjuvant treatment of breast cancer in postmenopausal women. Curr Med Res Opin 22(8):1609-1621
8. Massacesi C, Zepponi L, Rocchi M, Rossini S, Burattini L (2006) Tamoxifen-related endocrine symptoms in early breast cancer patients are relieved when it is switched to anastrozole. J Clin Oncol 24(18S June 20 Supplement): 10597

9. Edge S, Byrd D, Compton C, Fritz A, Greene F, Trotti A (eds) (2009) AJCC cancer staging manual, 7th edn. Springer, New York

10. Sobin L, Gospodarowicz M, Wittekind C (eds) (2009) UICC: TNM classification of malignant tumors, 7th edn. Wiley-Blackwell, Oxford

11. Guth U, Huang DJ, Schotzau A, Zanetti-Dallenbach R, Holzgreve W, Bitzer J, Wight E (2008) Target and reality of adjuvant endocrine therapy in postmenopausal patients with invasive breast cancer. Br J Cancer 99(3):428-433

12. Partridge AH, LaFountain A, Mayer E, Taylor BS, Winer E, Asnis-Alibozek A (2008) Adherence to initial adjuvant anastrozole therapy among women with early-stage breast cancer. J Clin Oncol 26(4):556-562

13. Partridge AH, Wang PS, Winer EP, Avorn J (2003) Nonadherence to adjuvant tamoxifen therapy in women with primary breast cancer. J Clin Oncol 21(4):602-606

14. Andrade SE, Kahler KH, Frech F, Chan KA (2006) Methods for evaluation of medication adherence and persistence using automated databases. Pharmacoepidemiol Drug Saf 15(8):565-574 Discussion 575-567

15. Barron TI, Connolly R, Bennett K, Feely J, Kennedy MJ (2007) Early discontinuation of tamoxifen: a lesson for oncologists. Cancer 109(5):832-839

16. Osterberg L, Blaschke T (2005) Adherence to medication. N Engl J Med 353(5):487-497

17. Coates AS, Keshaviah A, Thurlimann B, Mouridsen H, Mauriac L, Forbes JF, Paridaens R, Castiglione-Gertsch M, Gelber RD, Colleoni M et al (2007) Five years of letrozole compared with tamoxifen as initial adjuvant therapy for postmenopausal women with endocrine-responsive early breast cancer: update of study BIG 1-98. J Clin Oncol 25(5):486-492

18. Coombes RC, Hall E, Gibson LJ, Paridaens R, Jassem J, Delozier T, Jones SE, Alvarez I, Bertelli G, Ortmann O et al (2004) A randomized trial of exemestane after two to three years of tamoxifen therapy in postmenopausal women with primary breast cancer. N Engl J Med 350(11):1081-1092

19. Fisher B, Costantino J, Redmond C, Poisson R, Bowman D, Couture J, Dimitrov NV, Wolmark N, Wickerham DL, Fisher ER et al (1989) A randomized clinical trial evaluating tamoxifen in the treatment of patients with node-negative breast cancer who have estrogen-receptor-positive tumors. N Engl J Med 320(8): 479-484

20. Forbes JF, Cuzick J, Buzdar A, Howell A, Tobias JS, Baum M et al (2008) Effect of anastrozole and tamoxifen as adjuvant treatment for early-stage breast cancer: 100-month analysis of the ATAC trial. Lancet Oncol 9(1):45-53

21. Atkins L, Fallowfield L (2006) Intentional and non-intentional non-adherence to medication amongst breast cancer patients. Eur J Cancer 42(14):2271-2276

22. Demissie S, Silliman RA, Lash TL (2001) Adjuvant tamoxifen: predictors of use, side effects, and discontinuation in older women. J Clin Oncol 19(2):322-328

23. Fink AK, Gurwitz J, Rakowski W, Guadagnoli E, Silliman RA (2004) Patient beliefs and tamoxifen discontinuance in older women with estrogen receptor-positive breast cancer. J Clin Oncol 22(16):3309-3315

24. Grunfeld EA, Hunter MS, Sikka P, Mittal S (2005) Adherence beliefs among breast cancer patients taking tamoxifen. Patient Educ Couns 59(1):97-102

25. Hershman DL, Kushi LH, Shao T, Buono D, Kershenbaum A, Tsai WY, Fehrenbacher L, Lin Gomez S, Miles S, Neugut AI 
(2010) Early discontinuation and nonadherence to adjuvant hormonal therapy in a cohort of 8,769 early-stage breast cancer patients. J Clin Oncol 28(27):4120-4128

26. Lash TL, Fox MP, Westrup JL, Fink AK, Silliman RA (2006) Adherence to tamoxifen over the five-year course. Breast Cancer Res Treat 99(2):215-220

27. Owusu C, Buist DS, Field TS, Lash TL, Thwin SS, Geiger AM, Quinn VP, Frost F, Prout M, Yood MU et al (2008) Predictors of tamoxifen discontinuation among older women with estrogen receptor-positive breast cancer. J Clin Oncol 26(4):549-555

28. Silliman RA, Guadagnoli E, Rakowski W, Landrum MB, Lash TL, Wolf R, Fink A, Ganz PA, Gurwitz J, Borbas C et al (2002) Adjuvant tamoxifen prescription in women 65 years and older with primary breast cancer. J Clin Oncol 20(11):2680-2688

29. Waterhouse DM, Calzone KA, Mele C, Brenner DE (1993) Adherence to oral tamoxifen: a comparison of patient self-report, pill counts, and microelectronic monitoring. J Clin Oncol 11(6): 1189-1197
30. Ziller V, Kalder M, Albert US, Holzhauer W, Ziller M, Wagner U, Hadji P (2009) Adherence to adjuvant endocrine therapy in postmenopausal women with breast cancer. Ann Oncol 20(3): 431-436

31. Chlebowski RT, Geller ML (2006) Adherence to endocrine therapy for breast cancer. Oncology 71(1-2):1-9

32. Mallinger JB, Griggs JJ, Shields CG (2005) Patient-centered care and breast cancer survivors' satisfaction with information. Patient Educ Couns 57(3):342-349

33. Stewart M, Brown JB, Hammerton J, Donner A, Gavin A, Holliday RL, Whelan T, Leslie K, Cohen I, Weston W et al (2007) Improving communication between doctors and breast cancer patients. Ann Fam Med 5(5):387-394

34. Hadji P (2008) Menopausal symptoms and adjuvant therapyassociated adverse events. Endocr Relat Cancer 15(1):73-90

35. Vicary P, Johnson M, Maher J (2007) To my oncologist: an open letter from a patient at the end of follow-up. Clin Oncol (R Coll Radiol) 19(10):746-747 